\title{
Correlations of back muscle electromyography and gait analysis data as a basis for exercise prescription in patients with lumbar disc herniation
}

\author{
DOI: https://doi.org/10.5114/pq.2021.105753
}

\author{
Tigran Petrosyan', Hasmik Mkrtchyan², Naira Martirosyan', Arman Petrosyan', Haykanush Koloyan³, \\ Hananeh Majidi ${ }^{4}$, Mohamed Ismail ${ }^{4}$ \\ ${ }^{1}$ Department of Sports Medicine and Adaptive Sports, Yerevan State Medical University, Yerevan, Armenia \\ 2 Department of Kinesiology, Armenian State Institute of Physical Culture and Sport, Yerevan, Armenia \\ 3 'Armbiotechnology' Scientific and Production Centre SNPO NAS RA, Yerevan, Armenia \\ ${ }^{4}$ Department of General Medicine, Gorgan University of Medical Science, Gorgan, Iran
}

\section{Abstract}

Introduction. The principles and practice of physical rehabilitation in patients with lumbar disc herniation still remain controversial. The objective of the study was to reveal the correlations of gait pattern changes and muscle (spinal and leg muscles) electromyographic recordings in patients with lumbar disc herniation

Methods. A motion capture system was used to analyse gait parameters, including angular measurements of hip, knee, and ankle joints, foot support time, pace rate, and speed. A targeted exercise program with exercises in a shortened position of muscles without exceeding the internal range of contraction was applied to level the values of goniometric data and pace parameters obtained by motion capture.

Results. The gait restored owing to the reconditioning of spine and leg muscles, confirmed by the recorded changes in electromyographic data, ensures the irreversible nature of gait improvement. The changes in $\mathrm{H}$-reflex expression and muscle baseline electromyography of spine and leg muscles make up a proper tool that provides a system for periodic evaluation of gait recovery.

Conclusions. Targeting the weak muscles helped to identify the causes of gait deviations, revealing an expressed positive (negative) correlation between the targeted muscle strengthening and gait restoration. This confirms the importance of selective targeting and strengthening of the muscles to restore the deviated angles and other gait parameters.

Key words: intervertebral disk herniation, exercise, electromyography, motion capture, gait, targeted intervention

\section{Introduction}

Few clinical trials or reviews could be found in research databases trying to systemize the targeted rehabilitation process and yield physical rehabilitation protocols for patients with lumbar (or other) disc herniation. The current evidence for treatment of chronic low back pain shows that the implementation of targeted exercise programs for such patients is superior to the variety of combined therapies and can have a long-term impact on the disorder [1, 2]. The most common neurologic condition manifested with back pain is intervertebral disc herniation, and $95 \%$ of all cases occur at the L4-S1 levels. Identifying target muscles and joint movements can help design a physical rehabilitation program in a functionally specific and patient-focused manner, to significantly increase the efficacy of treatment.

The stabilizing system of the spinal cord is supported by the muscle system, which is also responsible for spine movements. Physical therapy of patients who have spinal pathology, including lumbar disc herniation, is usually concentrated on the restoration of joint functioning, and less attention is paid to muscles. However, normal locomotion depends on an appropriate biomechanical pattern of joints, sufficient spine muscle strength, and overall stability of the spine. In patients with lumbar pain syndrome and impaired gait resulting from disc herniation, the main diagnostic criteria that predict the rehabilitation strategy are strength and length measurements of back and lower extremity muscles. The role of muscle imbalance in gait impairment and pain syndrome has been extensively discussed in research publications [3-6]. Janda and Schmid [3] have classified spine muscles into 2 groups. The first group includes postural muscles (quadratus lumborum, erector spinae) and the second group muscles are referred to as phasic (rectus abdominis, internal and external obliques). Phasic muscles are considered to be antagonistic to the postural type. Injury and long inactivity result in a weakness of phasic muscles. This condition is described as stretch weakness, when a muscle remains in stretched condition for a long period but without an overstretching. A normally elongated muscle can produce peak tension in contraction with a $35 \%$ greater force, but 'weak' muscles after prolonged elongation are not able to produce additional tension [6]. Restoration of the initial muscle length could be achieved by exercising in its shortened position without exceeding its internal range of contraction. The goal of these exercises is not only to improve the muscle strength but also to restore the correct alignment of back segments. Motor responses to such imbalance in different segments range from insignificant postural deviation to impaired gait [7]. Pain forces the patients to take a position which will reduce the tissue stress and pain. Even when pain syndrome is resolved, the habitual change in posture continues to persist.

Changes in balanced posture and gait may occur for a variety of reasons. The most frequent cause of imbalance is

Correspondence address: Tigran Petrosyan, Department of Sports Medicine and Adaptive Sports, Yerevan State Medical University, 2 Koryun Street, Yerevan, Armenia, 0025, e-mail: tigran.petrosyan@sportedu.am 
overactivation of the limbic system due to emotional exertion and stress. The second cause of imbalance arises from developmental problems. Some individuals have poor motor control in general and are clumsy when performing physical tasks. Such individuals are often diagnosed with mild cerebral dysfunctions. Finally, a reduction of afferent input can result from different spinal pathologies, including intervertebral disc herniation. The main manifestations of lumbar disc herniation are back pain, eradiating pain in the leg, gait and posture alterations. The primary goal of therapy in patients with chronic compression syndrome is pain elimination. Pharmacotherapy resolves the pain if the size of herniation is not large, but gait impairment or compensatory gait develops.

Before prescribing an exercise therapy program, it is essential to assess the function of muscles. Electromyography (EMG) is the most appropriate and widely used tool to assess the state of skeletal muscles. Until the present state of muscles is evaluated, the patient's requirements for exercise cannot be estimated.

Muscle EMG activity changes during different movement elements. An increase in background firing activity induced by the movement is a precondition for the muscle activation and strengthening. Changes in the body or extremity position are applied to test the background activity of different muscles, identifying the optimum movement pattern (in the shortened position of muscles, but with increased and submaximal EMG activity). Coordinative activation of selected muscles (e.g. deep abdominals) by holding the pelvis in the correct position significantly increases the firing rate and amplitude (transversus abdominis muscle). Hip flexion following the verbal command further increases the EMG activity. Another example is stabilization of the lower left erector spinae muscle by applying concentric exercises for the left side, and eccentric exercises are used to induce downtraining on the right side. These EMG tests (registering muscle background activity) with changing body or extremity positions evaluate muscle activity before and after training sessions and programs.

$\mathrm{H}$-reflex is a valuable tool to assess changes in muscle tone and function. It could be very effective to analyse the efficacy of physiotherapy treatment, to plan exercise therapy, and to study some aspects of biomechanics. Albeck et al. [8] have revealed a high sensitivity and specificity of H-reflex in diagnosing $\mathrm{S} 1$ radiculopathy and disc herniation.

A decrease in $\mathrm{H}$-reflex amplitude is typical in the standing position, whereas in the prone position, the amplitude increases [9]. A large number of studies have confirmed the existing correlation between the reflex and postural modulation $[10,11]$. The amplitude of the H-reflex decreases in positions without back support. Even when the patient is standing without a support, the amplitude of the reflex is lower than in a sitting position without a support [12].

The $\mathrm{H}$-reflex evaluation is also applied in biomechanical studies. Different authors have examined $\mathrm{H}$-reflex amplitude changes after pedalling, ballistic, or strength training [13-15]. All researchers have reported decreased $\mathrm{H}$-reflex amplitude after the training period completion [14].

Larsen et al. [16] have studied EMG gait cycle changes in quadriceps. The registration of electrical signals from the muscle was performed for all gait phases, including the swing phase and foot support (heel contact). The authors showed that the H-reflex changed after foot support. The research conducted so far has focused more on cyclic changes of soleus H-reflex [17, 18]. Kyröläinen et al. [19] demonstrated that $\mathrm{H}$-reflex was a better index of muscle activity than maximal voluntary contraction. muscle imbalance and posture, which is altered in patients with spinal pathology, is gait. Different walking locomotion parameters are described by a large number of authors. The Vicon motion capture system consists of a group of videobased optoelectronic cameras used to capture and register the displacement of markers attached to special anatomical landmarks. Lower extremity kinematic data are registered [20] and evaluated to describe the gait pattern in patients with altered gait.

However, all these methods have certain limitations. Though angular measurements are still considered far from being perfect, modern motion capture systems that use multiple cameras (Vicon system with 12 cameras) provide a multidimensional analysis of joint range of motion, register precise foot support time, and monitor changes in these parameters occurring in a long period.

Dynamics of walking locomotion parameters (foot support time, speed, step length, step width, pacing rate) and a multiple comparison of their values after each exercise therapy session can estimate the exercise program efficacy.

To be sure about a complete efficacy of a strategy, it would be more rational to test the gait pattern changes with spine muscle activity. A change of muscle and motoneuron parameters towards the balanced activity and tone that correlate with improved gait can predict the more irreversible nature of physical rehabilitation.

The objective of the study was to reveal a correlation between gait pattern changes and muscle (spinal and leg muscles) EMG recordings (H-reflex and muscle baseline EMG) at different stages of physical rehabilitation. The recorded changes in EMG data from spine and leg muscles could constitute solid criteria for irreversible gait restoration in patients with lumbar intervertebral disc herniation. A standardized group of patients were involved in the study, with disc herniation at the same level (L4-S1) and the same parameters of herniation (size, direction). Discs can herniate in any direction - forward, centrally, and, most commonly, backwards (posterolaterally). Disc herniations at the L4-S1 level are almost always posterolateral in nature owing to the weakness of the posterior longitudinal ligament. In accordance with data presented by different authors, in $90-95 \%$ of cases, lumbar disc herniation is posterolateral [21] and the selection of a study group does not pose a difficult problem.

\section{Subjects and methods}

\section{Participants}

Overall, 24 patients aged $35-55$ years (the study did not include patients older than 55 years in order not to increase the rate of comorbidities in the study group) with intervertebral disc (L4-S1) herniation were involved in the study. The patient groups were standardized for age, sex, body mass index, and comorbidities (using the Functional Comorbidity Index [22] and such hernia parameters as location, size, and direction). The characteristics of patients in the study and control groups are shown in Table 1. The Functional Comorbidity Index contains diagnoses (18 conditions) such as arthritis and peripheral vascular disease, not found in the disease lists of other indices.

\section{Electromyography}

The $\mathrm{H}$-reflex from spine and leg muscles of patients was recorded before the exercise program, 3 weeks after the program initiation, and after the program completion (6 weeks). 
Table 1. Means and standard deviations for patient characteristics in both groups

\begin{tabular}{|c|c|c|c|c|}
\hline \multirow{2}{*}{ Characteristics } & \multicolumn{2}{|c|}{ Study group } & \multicolumn{2}{|c|}{ Control group } \\
\hline & Males & Females & Males & Females \\
\hline $\operatorname{Sex}(n)$ & 7 & 5 & 8 & 4 \\
\hline Age (years) & \multicolumn{2}{|c|}{$46.7 \pm 7.1$} & \multicolumn{2}{|c|}{$43.4 \pm 6.3$} \\
\hline BMI $\left(\mathrm{kg} / \mathrm{m}^{2}\right)$ & \multicolumn{2}{|c|}{$26.5 \pm 2.8$} & \multicolumn{2}{|c|}{$26.3 \pm 3.3$} \\
\hline Functional Comorbidity Index & \multicolumn{2}{|c|}{$1.7 \pm 1.2$} & \multicolumn{2}{|c|}{$1.5 \pm 1.3$} \\
\hline Hernia location & \multicolumn{2}{|c|}{ L4-S1 } & \multicolumn{2}{|c|}{ L4-S1 } \\
\hline Hernia size $(\mathrm{mm})$ & \multicolumn{2}{|c|}{$6.9 \pm 1.4$} & \multicolumn{2}{|c|}{$7.3 \pm 1.2$} \\
\hline Hernia direction & \multicolumn{2}{|c|}{ Posterolateral $^{*}$} & \multicolumn{2}{|c|}{ Posterolateral $^{*}$} \\
\hline Time after diagnosis & \multicolumn{2}{|c|}{ 0-3 months } & \multicolumn{2}{|c|}{$0-3$ months } \\
\hline Diagnosis method & \multicolumn{2}{|c|}{ Magnetic resonance } & \multicolumn{2}{|c|}{ Magnetic resonance } \\
\hline
\end{tabular}

* The side of the herniation is not specified as the purpose of the study was to analyse effects of a targeted exercise program based on electromyography and biomechanical data correlations.

The stimulation and registration of $\mathrm{H}$-reflex was conducted bilaterally for back and leg muscles. The EMG apparatus was set at $1000 \times-5000 \times(1-5 \mathrm{mV} /$ div. $)$ and a filter bandpass of $2 \mathrm{~Hz}-10 \mathrm{kHz}$ was applied to induce $\mathrm{H}$-reflex. The stimulation was maintained for $1.0 \mathrm{~ms}$, with a frequency of 0.2 pulse/s. A fixed distance was used between the stimulation and recording electrodes for all recording trials.

To maintain the maximum amplitude of H-reflex during the stimulation, a minimal M-wave amplitude was verified. When a minimal stimulus was applied, the M-wave was absent in the majority of tests and the $\mathrm{H}$-wave was maximal.

$\mathrm{H}$-wave is susceptible to the changes of posture. The same posture was maintained during the measurements. A change in posture altered the length of muscles, which resulted in a changed activity of muscle spindle receptors responsible for the $\mathrm{H}$-wave.

To control the recording procedure, all participants were asked to relax completely before data collection and keep the head in a neutral position. The procedure maximally reduced the variability of reflex amplitude. A total of 8-10 traces were induced and registered for each muscle of the patient and the 5 largest traces were selected for the analysis.

Activity testing was conducted before the program, 3 weeks after the program initiation, and after the program completion (6 weeks).
The background EMG activity from spine and leg muscles of patients was registered before the exercise program, 3 weeks after the program initiation, and after the program completion ( 6 weeks). The firing pattern was determined in the optimum movement pattern (shortened position of muscles, but with increased and submaximal EMG activity). Bipolar surface electrodes were located in the segment of muscle belly for leg muscles and in the middle segment of spinal muscles. The reference electrodes were fixed on the clavicle and the calcaneus. The received EMG signal was amplified (1000 times) and digitized (2000 samples/s). The registered background activity was band-pass filtered (50-500 Hz).

\section{Motion capture}

Experiments for evaluating the gait with the marker models were conducted in a special studio, equipped with a Vicon motion capture system [23]. The system consists of 12 high-speed and low-latency cameras.

The markers with a diameter of $14 \mathrm{~mm}$ and mass of $2 \mathrm{~g}$ are covered with a highly retroreflective material. The front of each camera has a strobe unit with light-emitting diodes to illuminate the markers. When a marker is inside the field of view, light rays from the strobe unit illuminate the marker and
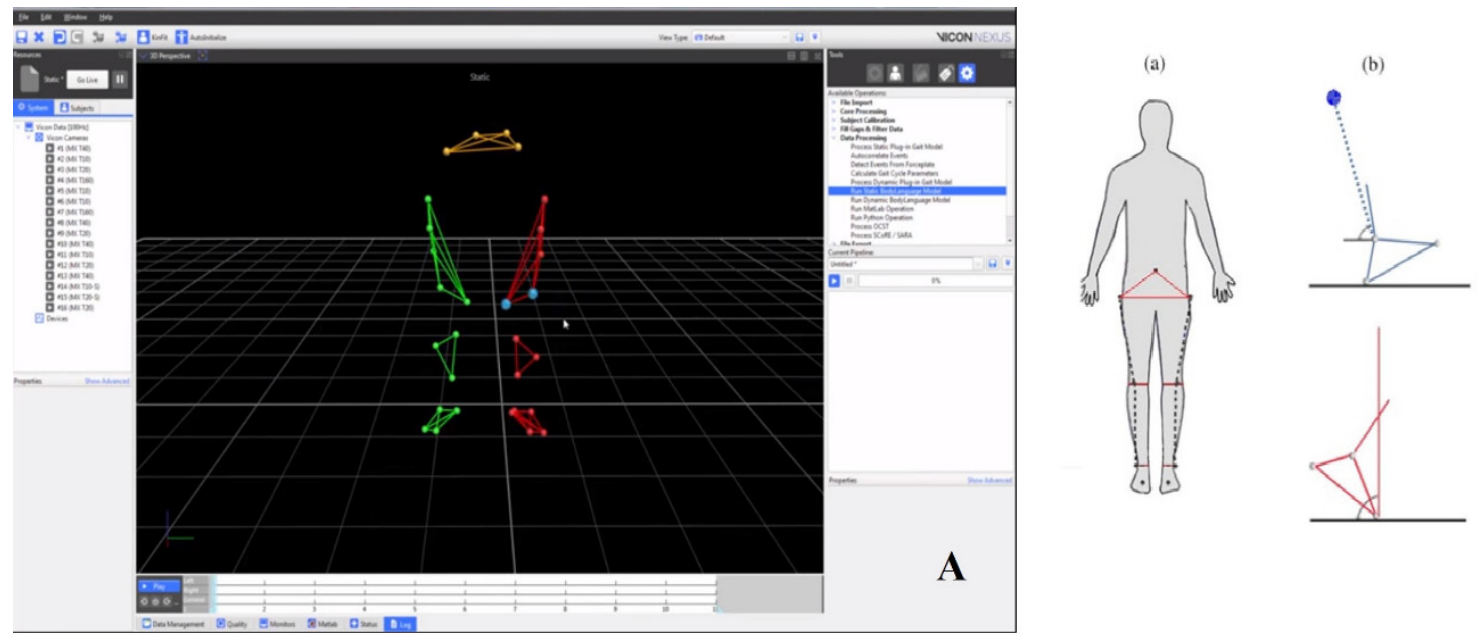

Figure 1. (A) Registering gait by the Nexus software. Blue-coloured markers show the left knee joint. (B) Angular measurements for gait analysis with the motion capture system: (a) position of markers, (b) measurements for the ankle joint, (c) measurements for the knee and hip joints. The angles presented in Figures (b) and (c) were applied for biomechanical analysis 
are reflected back to the camera lens. The image from each camera is then processed by the system, which results in a reconstruction of displacement trajectories of the markers in the 3-dimensional space. For successful reconstruction, each marker has to be tracked simultaneously by at least 2 cameras. Five markers were positioned on either leg and one marker was fixed on the abdominal midline, $5 \mathrm{~cm}$ below the umbilicus. The marker positions were chosen to provide data on the biomechanics of each leg segment and pelvis horizontal shift. Angular measurements at the ankle, knee, and hip joints were taken, as well as pace rate, speed, pace length, and foot support time analyses were performed by using special Vicon Nexus software (Figure 1).

The biomechanical study showed a clear forward shift of the pelvis, registered during the whole walking cycle. The tilt was caused by the weakness of the extensor muscles of the hip (for this reason, the quadratus lumborum and abdominal muscles were targeted). The significant forward tilt of the pelvis strengthens the extensor muscles of the hip joint, making it possible to maintain leg extension in walking. The higher the level of the spinal lesion, starting from L4-S1, the more the forward tilt increases with the level of herniation. The higher the herniation, the more expressed the tilt is. The maximum level (peak) of the forward pelvic tilt corresponded to $75 \%$ of the stance phase, when the hip flexors were used to compensate for the action of the plantar flexors.

\section{Exercise intervention program}

The program utilizes targeted exercises for muscles weakened by the disuse in a shortened position mode when the contraction range does not exceed its internal contraction range. This mode (without excessive muscle contraction) is essential for not causing muscle fatigue and for reducing the duration of sessions.

The training sessions were performed thrice a week for 12 weeks, 2-3 sets of 24 manoeuvres each. Each session lasted 60-90 minutes. In the first session, the patient performed $40-50 \%$ of the one-repetition maximum. One circuit consisted of 4-8 repetitions (depending on the stage) of the 24 manoeuvres, with a maximum 2-minute rest between the manoeuvre sets. The sessions started with a warm-up (aerobic) -5 minutes at low intensity, light free weight exercises using $20 \%$ of the usual workout weight, and pre-exercise stretching for 15-30 s, involving the muscles that would be used during the workout. After the warm-up, special (targeted) exercises were performed, starting with large or multiple muscle groups, and then engaging small muscle groups. The amount of weight for resistance exercises was $40-60 \%$ of one-repetition maximum. The rest period between workout sessions was 48 hours. The final part of the session (cooldown for 5-7 minutes) included post-exercise stretching to relax and elongate the muscles, which had become tight and short. Massage was applied to shorten the recovery time between the workouts. All training sessions were conducted by the same physical therapy instructors.

The exercises included in the study group program protocol targeted spinal and low extremity muscles. Not all exercises were neurologically L4-S1-segment specific (e.g. quadratus lumborum, abdominal muscles), but were targeted by the program to strengthen the muscle corset of the spine and to increase the low lumbar spine stability. The quadriceps and soleus muscles were targeted to evaluate changes in gait pattern.

The control group subjects were randomly assigned to planned individually by the therapists, without any additional instructions.

\section{Statistical analysis}

The statistical parameters (average value, standard deviation for angular measurements, pace parameters) used in the experiments were calculated with the Excel program. Statistically significant differences were determined by the Prism 3.03 computer program (GraphPad Software, Inc., USA). Multiple comparison was performed with Tukey's test. Pearson correlation served to test the relationship between biomechanical and EMG data.

\section{Ethical approval}

The research related to human use has complied with all the relevant national regulations and institutional policies, has followed the tenets of the Declaration of Helsinki, and has been approved by the ethics board and research committee at Yerevan State Medical University.

\section{Informed consent}

Informed consent has been obtained from all individuals included in this study.

\section{Results}

EMG data were recorded for the targeted muscles, including the amplitude and latency of $\mathrm{H}$-reflex from selected muscles, as well as their background EMG activity.

The patients' gait was evaluated by using the motion capture system, and data were collected for 17 gait parameters. The study group individuals $(n=12)$ underwent a special exercise therapy course designed to affect the targeted muscles. The control group included 12 patients with the same type of herniation who underwent double-blinded physical therapy treatment with different specialists. The therapists assigned to the control group did not receive any special instructions or protocols.

A statistically significant improvement was registered for the values of $\mathrm{H}$-reflex latency and amplitude, as well as the background EMG activity of selected muscles (Tables 2 and 3$)$. In the majority of registrations, the significance of difference was $p<0.05$. Data from Tables 2 and 3 show that in the control group, the patients' difference in pre- vs. postregistration values was not statistically significant. ANOVA with post-hoc Tukey's honestly significant difference (HSD) test were applied to compare the results of repeated measurements. The comparison revealed a non-constant difference between the repeated registrations in the study and control groups. Only for a proportion of muscle parameters was the difference in repeated testing data statistically significant $(p<0.05)$. The non-significant difference was due to the treatment (physical therapy intervention) that all control group patients were administered.

Gait analysis data of pre- and post-registration were compared between the study and control groups (Table 4). For 9 parameters (totally, 17 parameters were evaluated), a statistically significant difference $(p<0.05)$ was observed between the pre- and post-registration results in the study group, whereas in the control group, no statistically significant difference was revealed for any of the evaluated parameters. ANOVA with post-hoc Tukey's HSD test indicated a significant difference $(p<0.05)$ between the 2 groups only for 4 parameters. Greater $p$-values for the rest of gait parameters are again (as in the case of EMG data) due to the involvement 
Table 2. Means and standard deviations for H-reflex latency and amplitude registered from selected muscles of study and control group individuals

\begin{tabular}{|c|c|c|c|c|c|c|c|c|c|c|c|}
\hline \multirow{3}{*}{ Muscles } & \multirow{3}{*}{ Group } & \multicolumn{2}{|c|}{ Before the program } & \multicolumn{2}{|c|}{3 weeks after the start } & \multicolumn{2}{|c|}{$\begin{array}{l}\text { After the program } \\
\text { completion }\end{array}$} & \multicolumn{4}{|c|}{ Statistical significance } \\
\hline & & \multirow{2}{*}{$\begin{array}{l}\text { Latency } \\
\text { (ms) }\end{array}$} & \multirow{2}{*}{$\begin{array}{l}\text { Amplitude } \\
(\mathrm{mV})\end{array}$} & \multirow{2}{*}{$\begin{array}{l}\text { Latency } \\
\text { (ms) }\end{array}$} & \multirow{2}{*}{$\begin{array}{c}\text { Amplitude } \\
(\mathrm{mV})\end{array}$} & \multirow{2}{*}{$\begin{array}{l}\text { Latency } \\
\text { (ms) }\end{array}$} & \multirow{2}{*}{$\begin{array}{c}\text { Amplitude } \\
(\mathrm{mV})\end{array}$} & \multicolumn{2}{|c|}{$t$-test } & \multicolumn{2}{|c|}{ Tukey's HSD } \\
\hline & & & & & & & & Lat. & Amp. & Lat. & Amp. \\
\hline \multicolumn{12}{|l|}{ Spine muscles } \\
\hline \multirow{2}{*}{$\begin{array}{l}\text { Quadratus } \\
\text { lumborum }\end{array}$} & Study & $32.08 \pm 1.7$ & $3.2 \pm 0.7$ & $31.25 \pm 1.8$ & $3.6 \pm 0.9$ & $30.11 \pm 1.8$ & $3.8 \pm 0.7$ & $<0.05$ & $<0.05$ & \multirow{2}{*}{0.08} & \multirow{2}{*}{0.09} \\
\hline & Control & $33.14 \pm 2.2$ & $3.9 \pm 1.4$ & $32.68 \pm 3.8$ & $3.9 \pm 1.7$ & $32.10 \pm 3.4$ & $4.0 \pm 1.2$ & 0.38 & 0.43 & & \\
\hline \multirow{2}{*}{ Erector spinae } & Study & $31.16 \pm 1.5$ & $2.9 \pm 0.8$ & $30.67 \pm 1.4$ & $3.3 \pm 0.9$ & $29.75 \pm 1.4$ & $3.6 \pm 0.7$ & $<0.05$ & $<0.05$ & \multirow{2}{*}{0.37} & \multirow{2}{*}{0.01} \\
\hline & Control & $30.16 \pm 1.6$ & $4.3 \pm 0.9$ & $30.48 \pm 1.8$ & $4.3 \pm 1.1$ & $29.32 \pm 1.6$ & $4.4 \pm 1.2$ & 0.89 & 0.41 & & \\
\hline \multirow{2}{*}{ Rectus abdominis } & Study & $32.08 \pm 2.0$ & $4.9 \pm 0.8$ & $31.25 \pm 1.8$ & $5.1 \pm 0.8$ & $29.91 \pm 1.1$ & $5.3 \pm 0.9$ & $<0.05$ & 0.26 & \multirow{2}{*}{0.67} & \multirow{2}{*}{0.15} \\
\hline & Control & $31.62 \pm 2.4$ & $5.2 \pm 1.2$ & $31.88 \pm 2.8$ & $5.4 \pm 1.8$ & $30.72 \pm 3.4$ & $5.4 \pm 1.6$ & 0.46 & 0.74 & & \\
\hline \multirow{2}{*}{ Internal oblique } & Study & $32.66 \pm 1.2$ & $5.0 \pm 0.7$ & $31.83 \pm 0.7$ & $5.3 \pm 0.8$ & $31.00 \pm 0.9$ & $5.5 \pm 0.7$ & $<0.05$ & 0.09 & \multirow{2}{*}{0.77} & \multirow{2}{*}{0.02} \\
\hline & Control & $32.26 \pm 2.4$ & $5.8 \pm 1.2$ & $31.88 \pm 2.2$ & $5.8 \pm 1.0$ & $31.82 \pm 2.4$ & $5.9 \pm 1.6$ & 0.66 & 0.86 & & \\
\hline \multirow{2}{*}{ External oblique } & Study & $32.42 \pm 1.9$ & $5.1 \pm 0.7$ & $31.58 \pm 1.4$ & $5.3 \pm 0.6$ & $31.08 \pm 0.9$ & $5.5 \pm 0.5$ & $<0.05$ & 0.12 & \multirow{2}{*}{0.04} & \multirow{2}{*}{0.44} \\
\hline & Control & $33.18 \pm 1.9$ & $5.4 \pm 0.7$ & $33.06 \pm 1.7$ & $5.4 \pm 1.0$ & $32.68 \pm 2.2$ & $5.4 \pm 1.7$ & 0.55 & 1.0 & & \\
\hline \multicolumn{12}{|l|}{ Leg muscles } \\
\hline \multirow{2}{*}{ Quadriceps } & Study & $32.91 \pm 1.1$ & $4.8 \pm 0.6$ & $32.08 \pm 0.9$ & $5.08 \pm 0.5$ & $31.33 \pm 0.9$ & $5.4 \pm 0.8$ & $<0.05$ & 0.05 & \multirow{2}{*}{0.39} & \multirow{2}{*}{0.04} \\
\hline & Control & $32.62 \pm 2.4$ & $5.6 \pm 1.1$ & $32.42 \pm 2.8$ & $5.6 \pm 1.3$ & $32.62 \pm 1.8$ & $5.7 \pm 1.6$ & 1.0 & 0.86 & & \\
\hline & Study & $33.16 \pm 0.9$ & $3.6 \pm 1.1$ & $32.41 \pm 0.9$ & $4.0 \pm 0.9$ & $31.50 \pm 0.7$ & $4.6 \pm 0.8$ & $<0.05$ & $<0.05$ & 15 & ? \\
\hline 年 & Control & $32.10 \pm 0.9$ & $5.2 \pm 0.8$ & $31.96 \pm 2.7$ & $5.2 \pm 1.2$ & $31.78 \pm 1.4$ & $5.3 \pm 1.4$ & 0.52 & 0.83 & $0.4 \mathrm{~J}$ & 0.02 \\
\hline
\end{tabular}

HSD - honestly significant difference

Table 3. Means and standard deviations for the amplitude of background EMG activity registered from the trunk and leg muscles

\begin{tabular}{|c|c|c|c|c|c|c|}
\hline \multirow{2}{*}{ Muscles } & \multirow{2}{*}{ Group } & \multirow{2}{*}{$\begin{array}{c}\text { Before the program } \\
\begin{array}{c}\text { Amplitude } \\
(\mathrm{mV})\end{array}\end{array}$} & \multirow{2}{*}{$\begin{array}{c}3 \text { weeks after } \\
\text { the start }\end{array}$} & \multirow{2}{*}{$\begin{array}{c}\text { After the program } \\
\text { completion }\end{array}$} & \multicolumn{2}{|c|}{ Statistical significance } \\
\hline & & & & & $\begin{array}{c}t \text {-test } \\
p\end{array}$ & $\begin{array}{c}\text { Tukey's HSD } \\
p\end{array}$ \\
\hline \multicolumn{7}{|l|}{ Spine muscles } \\
\hline \multirow{2}{*}{ Quadratus lumborum } & Study & $21.5 \pm 1.4$ & $21.8 \pm 1.2$ & $23.4 \pm 1.0$ & $<0.05$ & \multirow{2}{*}{0.29} \\
\hline & Control & $22.6 \pm 2.4$ & $22.8 \pm 2.8$ & $23.8 \pm 2.4$ & 0.23 & \\
\hline \multirow{2}{*}{ Erector spinae } & Study & $16.0 \pm 1.4$ & $16.5 \pm 1.2$ & $17.0 \pm 1.2$ & 0.08 & \multirow{2}{*}{0.002} \\
\hline & Control & $18.8 \pm 2.2$ & $18.6 \pm 2.6$ & $19.1 \pm 3.2$ & 0.79 & \\
\hline \multirow{2}{*}{ Rectus abdominis } & Study & $22.8 \pm 1.4$ & $23.3 \pm 1.4$ & $24.4 \pm 1.7$ & $<0.05$ & \multirow{2}{*}{0.07} \\
\hline & Control & $21.6 \pm 3.2$ & $22.2 \pm 2.6$ & $22.6 \pm 2.4$ & 0.40 & \\
\hline \multirow{2}{*}{ Internal oblique } & Study & $33.5 \pm 3.1$ & $34.7 \pm 2.3$ & $35.7 \pm 2.5$ & 0.07 & \multirow{2}{*}{0.17} \\
\hline & Control & $32.2 \pm 4.8$ & $33.6 \pm 3.9$ & $33.9 \pm 3.2$ & 0.32 & \\
\hline \multirow{2}{*}{ External oblique } & Study & $45.5 \pm 7.8$ & $46.4 \pm 7.1$ & $48.3 \pm 6.1$ & 0.35 & \multirow{2}{*}{0.18} \\
\hline & Control & $47.8 \pm 5.8$ & $48.2 \pm 5.4$ & $48.2 \pm 6.4$ & 0.87 & \\
\hline \multicolumn{7}{|l|}{ Leg muscles } \\
\hline \multirow{2}{*}{ Quadriceps } & Study & $33.1 \pm 3.1$ & $34.3 \pm 3.2$ & $35.2 \pm 2.9$ & 0.10 & \multirow{2}{*}{0.35} \\
\hline & Control & $34.8 \pm 3.2$ & $34.6 \pm 2.8$ & $35.2 \pm 3.6$ & 0.77 & \\
\hline \multirow{2}{*}{ Soleus } & Study & $17.9 \pm 2.3$ & $19.0 \pm 2.2$ & $20.2 \pm 2.3$ & $<0.05$ & \multirow{2}{*}{0.9} \\
\hline & Control & $18.4 \pm 2.8$ & $18.6 \pm 2.6$ & $19.8 \pm 2.6$ & 0.22 & \\
\hline
\end{tabular}


Table 4. Means and standard deviations for kinematic and spatiotemporal gait parameters at baseline and 3 and 6 weeks after the baseline measurement

\begin{tabular}{|c|c|c|c|c|c|c|}
\hline Parameters & Group & Before the program & $\begin{array}{l}3 \text { weeks } \\
\text { after the start }\end{array}$ & $\begin{array}{l}\text { After the program } \\
\text { completion }\end{array}$ & $t$-test & $\begin{array}{c}\text { Tukey's } \\
\text { HSD }\end{array}$ \\
\hline \multicolumn{7}{|l|}{ Kinematic parameters } \\
\hline \multirow{2}{*}{$\begin{array}{l}\text { Horizontal shift of pelvis } \\
\text { at the target side }\left({ }^{\circ}\right)\end{array}$} & Study & $19.86 \pm 4.24$ & $17.34 \pm 3.18$ & $13.26 \pm 2.33$ & $<0.05$ & \multirow{2}{*}{0.73} \\
\hline & Control & $18.64 \pm 3.74$ & $17.26 \pm 2.66$ & $16.82 \pm 2.22$ & 0.16 & \\
\hline \multirow{2}{*}{$\begin{array}{l}\text { Maximum dorsiflexion } \\
\text { during stance phase }\left({ }^{\circ}\right)\end{array}$} & Study & $14.68 \pm 3.42$ & $15.11 \pm 3.33$ & $16.24 \pm 3.41$ & 0.27 & \multirow{2}{*}{0.05} \\
\hline & Control & $13.32 \pm 2.92$ & $13.61 \pm 3.10$ & $14.41 \pm 3.84$ & 0.45 & \\
\hline \multirow{2}{*}{$\begin{array}{l}\text { Maximum plantar flexion } \\
\text { during swing phase }\left({ }^{\circ}\right)\end{array}$} & Study & $12.92 \pm 5.72$ & $14.24 \pm 5.66$ & $15.78 \pm 6.26$ & 0.25 & \multirow{2}{*}{0.54} \\
\hline & Control & $13.24 \pm 3.16$ & $13.78 \pm 2.91$ & $14.16 \pm 3.12$ & 0.48 & \\
\hline \multirow{2}{*}{$\begin{array}{l}\text { Maximum knee flexion } \\
\text { during stance phase }\left({ }^{\circ}\right)\end{array}$} & Study & $15.23 \pm 3.24$ & $16.46 \pm 3.68$ & $18.25 \pm 3.75$ & $<0.05$ & \multirow{2}{*}{0.11} \\
\hline & Control & $14.38 \pm 2.68$ & $14.43 \pm 2.86$ & $15.32 \pm 3.12$ & 0.43 & \\
\hline \multirow{2}{*}{$\begin{array}{l}\text { Maximum knee extension } \\
\text { during terminal stance phase }\left({ }^{\circ}\right)\end{array}$} & Study & $7.60 \pm 1.16$ & $8.66 \pm 1.88$ & $9.28 \pm 1.64$ & $<0.05$ & \multirow{2}{*}{0.88} \\
\hline & Control & $8.24 \pm 2.28$ & $8.82 \pm 2.12$ & $8.72 \pm 1.84$ & 0.57 & \\
\hline \multirow{2}{*}{$\begin{array}{l}\text { Maximum knee flexion } \\
\text { during swing phase }\left(^{\circ}\right)\end{array}$} & Study & $48.67 \pm 6.16$ & $53.67 \pm 9.12$ & $61.90 \pm 9.68$ & $<0.05$ & \multirow{2}{*}{0.62} \\
\hline & Control & $50.42 \pm 4.48$ & $52.49 \pm 6.33$ & $54.82 \pm 6.36$ & 0.06 & \\
\hline \multirow{2}{*}{$\begin{array}{l}\text { Maximum knee extension } \\
\text { adjacent to heel strike }\left({ }^{\circ}\right)\end{array}$} & Study & $6.98 \pm 1.12$ & $8.14 \pm 1.46$ & $10.24 \pm 2.18$ & $<0.05$ & \multirow{2}{*}{0.43} \\
\hline & Control & $7.12 \pm 2.18$ & $7.24 \pm 1.96$ & $8.28 \pm 2.22$ & 0.21 & \\
\hline \multirow{2}{*}{$\begin{array}{l}\text { Hip flexion during stance phase - } \\
\text { foot flat }\left({ }^{\circ}\right)\end{array}$} & Study & $19.24 \pm 4.74$ & $22.68 \pm 4.64$ & $25.34 \pm 4.20$ & $<0.05$ & \multirow{2}{*}{0.86} \\
\hline & Control & $21.16 \pm 4.68$ & $22.42 \pm 4.74$ & $22.68 \pm 3.68$ & 0.38 & \\
\hline \multirow{2}{*}{$\begin{array}{l}\text { Hip flexion during stance phase } \\
\text { - heal off }\left({ }^{\circ}\right)\end{array}$} & Study & $15.44 \pm 3.62$ & $17.12 \pm 4.20$ & $20.36 \pm 4.26$ & $<0.05$ & \multirow{2}{*}{0.18} \\
\hline & Control & $14.32 \pm 3.20$ & $14.88 \pm 3.92$ & $16.22 \pm 3.48$ & 0.18 & \\
\hline \multirow{2}{*}{$\begin{array}{l}\text { Maximum hip extension } \\
\text { during midstance phase }\left({ }^{\circ}\right)\end{array}$} & Study & $8.12 \pm 1.62$ & $9.38 \pm 2.14$ & $9.68 \pm 2.36$ & 0.07 & \multirow{2}{*}{0.15} \\
\hline & Control & $7.84 \pm 1.82$ & $8.12 \pm 2.42$ & $8.48 \pm 2.68$ & 0.49 & \\
\hline \multirow{2}{*}{$\begin{array}{l}\text { Maximum hip flexion during } \\
\text { swing phase - heal strike }\left({ }^{\circ}\right)\end{array}$} & Study & $23.84 \pm 4.16$ & $26.56 \pm 4.88$ & $32.84 \pm 6.12$ & $<0.05$ & \multirow{2}{*}{0.77} \\
\hline & Control & $25.62 \pm 4.32$ & $26.88 \pm 4.82$ & $28.14 \pm 5.22$ & 0.20 & \\
\hline \multicolumn{7}{|l|}{ Spatiotemporal parameters } \\
\hline \multirow{2}{*}{ Gait speed $(\mathrm{m} / \mathrm{s})$} & Study & $1.18 \pm 0.24$ & $1.26 \pm 0.20$ & $1.27 \pm 0.20$ & 0.32 & \multirow{2}{*}{0.03} \\
\hline & Control & $1.32 \pm 0.46$ & $1.34 \pm 0.64$ & $1.36 \pm 0.42$ & 0.83 & \\
\hline \multirow{2}{*}{ Cadence (steps/min) } & Study & $109.65 \pm 8.72$ & $112.65 \pm 8.44$ & $112.54 \pm 8.75$ & 0.42 & 0 \\
\hline & Control & $106.23 \pm 7.96$ & $108.63 \pm 7.86$ & $108.88 \pm 7.48$ & 0.41 & 0.040 \\
\hline & Study & $0.63 \pm 0.10$ & $0.65 \pm 0.08$ & $0.67 \pm 0.08$ & 0.29 & \\
\hline SIEP IEnguा (III) & Control & $0.60 \pm 0.14$ & $0.64 \pm 0.18$ & $0.65 \pm 0.24$ & 0.54 & 0.00 \\
\hline & Study & $38.47 \pm 2.38$ & $39.09 \pm 1.85$ & $39.52 \pm 1.86$ & 0.25 & \\
\hline (1) & Control & $39.64 \pm 4.28$ & $40.12 \pm 4.18$ & $40.42 \pm 4.26$ & 0.66 & 0.00 \\
\hline & Study & $1.12 \pm 0.16$ & $1.08 \pm 007$ & $1.02 \pm 0.06$ & 0.06 & \\
\hline & Control & $1.04 \pm 0.08$ & $1.06 \pm 0.04$ & $1.06 \pm 0.08$ & 0.55 & 0.04 \\
\hline gle sı & Study & $1.11 \pm 0.12$ & $1.08 \pm 0.04$ & $1.04 \pm 0.03$ & 0.07 & \\
\hline index $^{*}$ & Control & $1.14 \pm 0.14$ & $1.12 \pm 0.10$ & $1.10 \pm 0.09$ & 0.41 & 0.14 \\
\hline
\end{tabular}

HSD - honestly significant difference

54 *In the case of absolute symmetry, the index equals 1. 
Table 5. Exercises included in the intervention program

\begin{tabular}{|l|l|}
\hline \multicolumn{2}{|l|}{ Spine muscles } \\
\hline $\begin{array}{l}\text { Quadratus } \\
\text { lumborum }\end{array}$ & $\begin{array}{l}\text { 1. Side plank } \\
\text { 2. Cat-cow exercise } \\
\text { 3. Asymmetric weight carrying }\end{array}$ \\
\hline Erector spinae & $\begin{array}{l}\text { 1. Deadlift } \\
\text { 2. Back extension with stability ball } \\
\text { 3. Superman exercise }\end{array}$ \\
\hline Rectus abdominis & $\begin{array}{l}\text { 1. Sit-ups } \\
\text { 2. Isometric contraction and tightening } \\
\text { of abdominal muscles }\end{array}$ \\
\hline 3. Toe-touch crunch
\end{tabular}

of the control group patients in 'alternative' methods of physical therapy. The therapists conducting the treatment sessions in the control group were experienced professionals from different rehabilitation medicine departments where the study participants underwent the therapy. Our study does not compare the presented (targeted) approach (Table 5) with a certain mode of therapy, but all physiotherapists working with the control group patients used generally accepted methods and protocols in the physical rehabilitation of patients with lumbar disc herniation: restoring spinal and lower extremity flexibility, restoring spinal and lower extremity muscular strength, stabilization exercises, functional lifting, bending and reaching activities with light resistance. Patients of both groups did not receive pharmacotherapy during the study period.

Pearson correlation was calculated between the gait parameters and EMG data ( $\mathrm{H}$-reflex latency and amplitude, background EMG activity) of 7 muscles (Tables 6-8). Almost all parameters exhibited a higher (closer to 1 or -1 ) correlation coefficient in the study group. The correlation values of the control and study groups were compared to show the level of difference between the groups. For all the parameters, the difference between the correlation data of the 2 groups was statistically significant $(p<0.05)$.

\section{Discussion}

The goal of the project was to test the efficacy of targeted physical rehabilitation in patients with lumbar intervertebral disc herniation. EMG data from lower extremity muscle groups responsible for moments/forces controlling the gait were used to target the weak muscles and strengthen them. A strengthening exercise program can lead to gait remodelling. Widely used tests for muscle weakness or reduced muscle strength are not objective when performed by a non-experienced therapist or by different specialists in the same group and may lead to bias in data collection and analysis. In contrast, a kinematic analysis of gait with the use of a motion capture system is a rather precise method and reveals the actual function of the targeted muscle groups involved in gait control. Evidence from earlier studies confirms the hypothesis that joint moments typical of normal gait are reduced in patients with lumbar disc herniations $[24,25]$. The researchers confirmed the hypothesis and showed that the changes in gait-specific moments were correlated with the size and level of the lesion. The study group implied that moments for gait components such as the external plantar flexion, dorsiflexion, and knee extension were reduced in the L5-S1 group, whereas in patients with herniation at the L4-L5 level, the only moment reduced was in external plantar flexion $[16,26]$.

The above-mentioned moments registered during gait are all external forces, and are opposite the internal moments primarily generated by different muscle groups. Patients with herniations at L4-L5 had decreased dorsiflexor muscle moments, whereas those with herniations at L5-S1 had a deficit in moments generated by the dorsiflexors, plantar flexors, and knee flexors. The reduced external ankle plantar flexion moment indicates a decreased function of the foot dorsiflexors. The muscle group of ankle dorsiflexors controls the motion of lowering the foot to the ground, described as a phase between heel strike and foot flat. Topographically, the herniation of the L4-L5 intervertebral disc affects primarily the fifth lumbar root. The muscle group of foot dorsiflexors are mainly innervated by the fifth lumbar root, also receiving branches from the fourth lumbar and the first sacral roots. Thus, it is expected that herniations of the L4-L5 and L5-S1 discs will be associated with reduced function of the foot dorsiflexors. Gait abnormalities are always consistent with the nerve root involvement. Reduced external ankle dorsiflexion and knee extension moments at late stance are typical in patients with L5-S1 disc herniations, reducing the function of the foot plantar flexors, which generate the propulsive force at the push-off phase of gait. To confirm the hypothesis that the differences in joint moments were correlated with the level of disc lesion and not generated by other factors (e.g. pain, local swelling or inflammation of soft tissues, vascular conditions), the researchers also tested the peak knee flexion moment, generated and sustained by knee flexors. The quadriceps muscle moment (responsible for external knee flexion moment) was not reduced in patients with intervertebral herniation, as neither the L4-L5 nor the L5-S1 herniation induces nerve compression or injury that might result in such alteration.

Reshaping gait by targeting the above-mentioned leg muscles is not enough to reach permanent stability: core stabilization with strengthening of abdominal and lumbar muscles is indispensable. The EMG data in this study helped to identify the weakened muscles in the leg and trunk. Strengthening the targeted muscles by a selectively planned exercise program reshaped the gait of patients with lumbar disc herniation. The gait reshaping in the study group was monitored with a motion capture system and confirmed by the statistical correlational analysis of kinematic and EMG data.

\section{Conclusions}

Targeting the weak muscles helped to identify the causes of gait deviations, revealing an expressed positive (or negative) correlation between the targeted muscle strengthening and gait restoration. This confirms the importance of selective targeting and strengthening of the muscles to restore the deviated angles and other gait parameters. 
Table 6. Correlation between gait parameters and H-reflex latency for different muscles

\begin{tabular}{|c|c|c|c|c|c|c|c|c|c|}
\hline Parameters & Group & $\begin{array}{l}\text { Quadratus } \\
\text { lumborum }\end{array}$ & $\begin{array}{l}\text { Erector } \\
\text { spinae }\end{array}$ & $\begin{array}{c}\text { Rectus } \\
\text { abdominis }\end{array}$ & $\begin{array}{l}\text { Internal } \\
\text { oblique }\end{array}$ & $\begin{array}{l}\text { External } \\
\text { oblique }\end{array}$ & Quadriceps & Soleus & $p$ \\
\hline \multicolumn{10}{|l|}{ Kinematic parameters } \\
\hline \multirow{2}{*}{$\begin{array}{l}\text { Horizontal shift of pelvis } \\
\text { at the target side }\left(^{\circ}\right)\end{array}$} & Study & 0.99 & 0.99 & 0.99 & 0.99 & 0.96 & 0.98 & 0.99 & \multirow{2}{*}{$<0.05$} \\
\hline & Control & 0.93 & 0.47 & 0.52 & 0.98 & 0.83 & 0.29 & 0.93 & \\
\hline \multirow{2}{*}{$\begin{array}{l}\text { Maximum dorsiflexion } \\
\text { during stance phase }\left({ }^{\circ}\right)\end{array}$} & Study & -0.99 & -0.99 & -0.99 & -0.99 & -0.98 & -0.99 & -0.99 & \multirow{2}{*}{$<0.05$} \\
\hline & Control & -0.98 & -0.86 & -0.88 & -0.79 & -0.91 & 0.26 & -0.98 & \\
\hline \multirow{2}{*}{$\begin{array}{l}\text { Maximum plantar flexion } \\
\text { during swing phase }\left({ }^{\circ}\right)\end{array}$} & Study & -0.99 & -0.99 & -0.99 & -0.99 & -0.97 & -0.99 & -0.99 & \multirow{2}{*}{$<0.05$} \\
\hline & Control & -0.98 & -0.63 & -0.67 & -0.95 & -0.92 & -0.10 & -0.96 & \\
\hline \multirow{2}{*}{$\begin{array}{l}\text { Maximum knee flexion } \\
\text { during stance phase }\left({ }^{\circ}\right)\end{array}$} & Study & -0.99 & -0.99 & -0.99 & -0.99 & -0.97 & -0.99 & -0.99 & \multirow{2}{*}{$<0.05$} \\
\hline & Control & -0.92 & -0.95 & -0.96 & -0.64 & -0.98 & -0.46 & -0.92 & \\
\hline \multirow{2}{*}{$\begin{array}{l}\text { Maximum knee extension } \\
\text { during terminal stance phase }\left({ }^{\circ}\right)\end{array}$} & Study & -0.97 & -0.95 & -0.96 & -0.99 & -0.99 & -0.99 & -0.98 & \multirow{2}{*}{$<0.05$} \\
\hline & Control & -0.73 & -0.09 & -0.15 & -0.95 & -0.56 & -0.63 & -0.73 & \\
\hline \multirow{2}{*}{$\begin{array}{l}\text { Maximum knee flexion during } \\
\text { swing phase }\left({ }^{\circ}\right)\end{array}$} & Study & -0.99 & 0.99 & -0.99 & -0.99 & -0.96 & -0.99 & -0.99 & \multirow{2}{*}{$<0.05$} \\
\hline & Control & -0.99 & -0.72 & -0.76 & -0.90 & -0.96 & 0.03 & -0.99 & \\
\hline \multirow{2}{*}{$\begin{array}{l}\text { Maximum knee extension } \\
\text { adjacent to heel strike }\left({ }^{\circ}\right)\end{array}$} & Study & -0.99 & -0.99 & -0.99 & -0.99 & -0.95 & -0.98 & -0.99 & \multirow{2}{*}{$<0.05$} \\
\hline & Control & -0.93 & -0.93 & -0.95 & -0.68 & -0.99 & -0.42 & -0.93 & \\
\hline \multirow{2}{*}{$\begin{array}{l}\text { Hip flexion during stance phase } \\
\text { - foot flat }\left(^{\circ}\right)\end{array}$} & Study & -0.99 & -0.97 & -0.98 & -0.99 & -0.99 & -0.99 & -0.99 & \multirow{2}{*}{$<0.05$} \\
\hline & Control & -0.90 & -0.40 & -0.45 & -0.99 & -0.79 & -0.35 & -0.91 & \\
\hline \multirow{2}{*}{$\begin{array}{l}\text { Hip flexion during stance phase } \\
\text { - heal off }\left({ }^{\circ}\right)\end{array}$} & Study & -0.99 & -0.99 & -0.99 & -0.98 & -0.95 & -0.98 & -0.99 & \multirow{2}{*}{$<0.05$} \\
\hline & Control & -0.98 & -0.85 & -0.87 & -0.81 & -0.99 & 0.23 & -0.98 & \\
\hline \multirow{2}{*}{$\begin{array}{l}\text { Maximum hip extension during } \\
\text { midstance phase }\left({ }^{\circ}\right)\end{array}$} & Study & -0.91 & -0.87 & -0.88 & -0.94 & -0.98 & -0.95 & -0.92 & \multirow{2}{*}{$<0.05$} \\
\hline & Control & -0.99 & -0.75 & -0.78 & -0.89 & -0.97 & 0.07 & -1.0 & \\
\hline \multirow{2}{*}{$\begin{array}{l}\text { Maximum hip flexion during } \\
\text { swing phase - heal strike }\left({ }^{\circ}\right)\end{array}$} & Study & -0.99 & -0.99 & -0.99 & -0.97 & -0.93 & -0.97 & -0.99 & \multirow{2}{*}{$<0.05$} \\
\hline & Control & -0.99 & -0.70 & -0.74 & -0.92 & -0.96 & -0.02 & -0.99 & \\
\hline \multicolumn{10}{|l|}{ Spatiotemporal parameters } \\
\hline \multirow{2}{*}{ Gait speed $(\mathrm{m} / \mathrm{s})$} & Study & -0.87 & -0.83 & -0.84 & -0.92 & -0.96 & -0.92 & -0.89 & \multirow{2}{*}{$<0.05$} \\
\hline & Control & -0.99 & -0.70 & -0.74 & -0.92 & -0.96 & -0.02 & -0.99 & \\
\hline & Study & -0.80 & -0.75 & -0.77 & -0.85 & -0.92 & -0.86 & -0.82 & \\
\hline vadence (steps/min) & Control & -0.87 & -0.33 & -0.38 & -0.99 & -0.75 & -0.42 & -0.87 & $<0.00$ \\
\hline & Study & -0.99 & -0.98 & -0.99 & -1.0 & -0.99 & -0.99 & -0.99 & \\
\hline Jep lengtir) (III) & Control & -0.92 & -0.43 & -0.48 & -0.99 & -0.81 & -0.33 & -0.92 & $<0.00$ \\
\hline & Study & 0.99 & 0.99 & 0.99 & 0.99 & 0.97 & 0.99 & 0.99 & \\
\hline 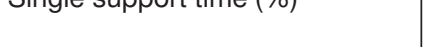 & Control & -0.98 & -0.60 & -0.64 & -0.96 & -0.91 & -0.13 & -0.98 & $<0.00$ \\
\hline O & Study & 0.99 & 0.99 & 0.99 & 0.99 & 0.97 & 0.99 & 0.99 & $\sigma_{0}$ \\
\hline 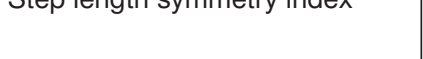 & Control & -0.83 & -0.25 & -0.30 & -0.99 & -0.68 & -0.50 & -0.82 & $<0.00$ \\
\hline Single support time symmetry & Study & 0.99 & 0.99 & 0.99 & 0.99 & 0.97 & 0.99 & 0.99 & \\
\hline index & Control & 0.99 & 0.70 & 0.74 & 0.92 & 0.96 & 0.01 & 0.99 & $<0.00$ \\
\hline
\end{tabular}

* In the case of absolute symmetry, the index equals 1. 
Table 7. Correlation between gait parameters and H-reflex amplitude for different muscles

\begin{tabular}{|c|c|c|c|c|c|c|c|c|c|}
\hline Parameters & Group & $\begin{array}{l}\text { Quadratus } \\
\text { lumborum }\end{array}$ & $\begin{array}{l}\text { Erector } \\
\text { spinae }\end{array}$ & $\begin{array}{c}\text { Rectus } \\
\text { abdominis }\end{array}$ & $\begin{array}{l}\text { Internal } \\
\text { oblique }\end{array}$ & $\begin{array}{l}\text { External } \\
\text { oblique }\end{array}$ & Quadriceps & Soleus & $p$ \\
\hline \multicolumn{10}{|l|}{ Kinematic parameters } \\
\hline \multirow{2}{*}{$\begin{array}{l}\text { Horizontal shift of pelvis } \\
\text { at the target side }\left(^{\circ}\right)\end{array}$} & Study & -0.95 & -0.98 & -0.99 & -0.97 & -0.99 & -0.99 & -0.99 & \multirow{2}{*}{$<0.05$} \\
\hline & Control & -0.68 & -0.69 & -0.97 & -0.69 & 0.29 & -0.69 & -0.69 & \\
\hline \multirow{2}{*}{$\begin{array}{l}\text { Maximum dorsiflexion } \\
\text { during stance phase }\left({ }^{\circ}\right)\end{array}$} & Study & 0.90 & 0.94 & 0.97 & 0.93 & 0.97 & 0.98 & 0.99 & \multirow{2}{*}{$<0.05$} \\
\hline & Control & 0.96 & 0.96 & 0.71 & 0.96 & 0.26 & 0.97 & 0.97 & \\
\hline \multirow{2}{*}{$\begin{array}{l}\text { Maximum plantar flexion } \\
\text { during swing phase }\left(^{\circ}\right)\end{array}$} & Study & 0.97 & 0.99 & 0.99 & 0.99 & 0.99 & 0.99 & 0.99 & \multirow{2}{*}{$<0.05$} \\
\hline & Control & 0.81 & 0.81 & 0.91 & 0.81 & -0.10 & 0.81 & 0.81 & \\
\hline \multirow{2}{*}{$\begin{array}{l}\text { Maximum knee flexion } \\
\text { during stance phase }\left({ }^{\circ}\right)\end{array}$} & Study & 0.96 & 0.98 & 0.99 & 0.98 & 0.99 & 0.99 & 0.99 & \multirow{2}{*}{$<0.05$} \\
\hline & Control & 0.99 & 0.99 & 0.54 & 0.99 & 0.46 & 0.99 & 0.99 & \\
\hline \multirow{2}{*}{$\begin{array}{l}\text { Maximum knee extension } \\
\text { during terminal stance phase }\left({ }^{\circ}\right)\end{array}$} & Study & 0.99 & 0.99 & 0.99 & 0.99 & 0.99 & 0.98 & 0.97 & \multirow{2}{*}{$<0.05$} \\
\hline & Control & 0.35 & 0.35 & 0.98 & 0.35 & -0.63 & 0.35 & 0.35 & \\
\hline \multirow{2}{*}{$\begin{array}{l}\text { Maximum knee flexion } \\
\text { during swing phase }\left({ }^{\circ}\right)\end{array}$} & Study & 0.95 & 0.96 & 0.99 & 0.98 & 0.99 & 0.99 & 0.99 & \multirow{2}{*}{$<0.05$} \\
\hline & Control & 0.88 & 0.88 & 0.85 & 0.88 & 0.03 & 0.88 & 0.88 & \\
\hline \multirow{2}{*}{$\begin{array}{l}\text { Maximum knee extension } \\
\text { adjacent to heel strike }\left({ }^{\circ}\right)\end{array}$} & Study & 0.94 & 0.97 & 0.99 & 0.96 & 0.99 & 0.99 & 0.99 & \multirow{2}{*}{$<0.05$} \\
\hline & Control & 0.99 & 0.99 & 0.58 & 0.99 & 0.42 & 0.99 & 0.99 & \\
\hline \multirow{2}{*}{$\begin{array}{l}\text { Hip flexion during stance phase } \\
\text { - foot flat }\left(^{\circ}\right)\end{array}$} & Study & 0.99 & 0.99 & 0.99 & 0.99 & 0.99 & 0.99 & 0.98 & \multirow{2}{*}{$<0.05$} \\
\hline & Control & 0.63 & 0.63 & 0.98 & 0.63 & -0.35 & 0.63 & 0.63 & \\
\hline \multirow{2}{*}{$\begin{array}{l}\text { Hip flexion during stance phase } \\
\text { - heal off }\left(^{\circ}\right)\end{array}$} & Study & 1.0 & 1.0 & 1.0 & 1.0 & 1.0 & 1.0 & 0.99 & \multirow{2}{*}{$<0.05$} \\
\hline & Control & 0.96 & 0.96 & 0.73 & 0.96 & 0.23 & 0.96 & 0.96 & \\
\hline \multirow{2}{*}{$\begin{array}{l}\text { Maximum hip extension } \\
\text { during midstance phase }\left(^{\circ}\right)\end{array}$} & Study & 0.99 & 0.97 & 0.94 & 0.97 & 0.94 & 0.93 & 0.90 & \multirow{2}{*}{$<0.05$} \\
\hline & Control & 0.90 & 0.90 & 0.83 & 0.90 & 0.07 & 0.90 & 0.90 & \\
\hline \multirow{2}{*}{$\begin{array}{l}\text { Maximum hip flexion during } \\
\text { swing phase - heal strike }\left({ }^{\circ}\right)\end{array}$} & Study & 0.92 & 0.95 & 0.97 & 0.94 & 0.97 & 0.98 & 0.99 & \multirow{2}{*}{$<0.05$} \\
\hline & Control & 0.87 & 0.87 & 0.87 & 0.87 & 0.01 & 0.87 & 0.87 & \\
\hline \multicolumn{10}{|l|}{ Spatiotemporal parameters } \\
\hline \multirow{2}{*}{ Gait speed (m/s) } & Study & 0.97 & 0.94 & 0.91 & 0.95 & 0.91 & 0.90 & 0.86 & \multirow{2}{*}{$<0.05$} \\
\hline & Control & 0.87 & 0.87 & 0.87 & 0.87 & 0.01 & 0.87 & 0.87 & \\
\hline & Study & 0.93 & 0.89 & 0.85 & 0.90 & 0.85 & 0.83 & 0.79 & \\
\hline (2) & Control & 0.57 & 0.57 & 0.99 & 0.57 & -0.42 & 0.57 & 0.57 & -0.00 \\
\hline & Study & 0.98 & 0.99 & 1.0 & 0.99 & 1.0 & 0.99 & 0.99 & \\
\hline & Control & 0.65 & 0.65 & 0.98 & 0.65 & -0.34 & 0.65 & 0.65 & \\
\hline & Study & 0.99 & 0.99 & 0.99 & 0.99 & 0.99 & 0.99 & 0.98 & \\
\hline (1) & Control & 0.80 & 0.80 & 0.92 & 0.80 & -0.13 & 0.80 & 0.80 & $<0.00$ \\
\hline & Study & -0.95 & -0.98 & -0.99 & -0.97 & -0.99 & -0.99 & 1.0 & \\
\hline 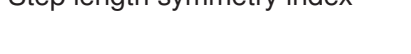 & Control & 0.50 & 0.50 & 0.87 & 0.50 & -0.50 & 0.50 & 0.50 & -0.00 \\
\hline Single support time symmetry & Study & -0.96 & -0.99 & -0.99 & -0.98 & -0.99 & -0.99 & -0.99 & \\
\hline index* & Control & -0.87 & -0.87 & -0.87 & -0.87 & 0.12 & -0.87 & -0.87 & -0.00 \\
\hline
\end{tabular}

* In the case of absolute symmetry, the index equals 1 . 
Table 8. Correlation between gait parameters and the average amplitude of background electromyographic activity for different muscles

\begin{tabular}{|c|c|c|c|c|c|c|c|c|c|}
\hline Parameters & Group & $\begin{array}{l}\text { Quadratus } \\
\text { lumborum }\end{array}$ & $\begin{array}{l}\text { Erector } \\
\text { spinae }\end{array}$ & $\begin{array}{c}\text { Rectus } \\
\text { abdominis }\end{array}$ & $\begin{array}{l}\text { Internal } \\
\text { oblique }\end{array}$ & $\begin{array}{l}\text { External } \\
\text { oblique }\end{array}$ & Quadriceps & Soleus & $p$ \\
\hline \multicolumn{10}{|l|}{ Kinematic parameters } \\
\hline \multirow{2}{*}{$\begin{array}{l}\text { Horizontal shift of pelvis } \\
\text { at the target side }\left({ }^{\circ}\right)\end{array}$} & Study & -0.97 & -0.99 & -0.99 & -0.98 & -0.99 & -0.98 & 0.99 & \multirow{2}{*}{$<0.05$} \\
\hline & Control & -0.79 & -0.84 & -0.98 & -0.99 & -0.97 & -0.41 & -0.34 & \\
\hline \multirow{2}{*}{$\begin{array}{l}\text { Maximum dorsiflexion } \\
\text { during stance phase }\left(^{\circ}\right)\end{array}$} & Study & 0.99 & 0.97 & 0.99 & 0.95 & 0.99 & 0.94 & 0.97 & \multirow{2}{*}{$<0.05$} \\
\hline & Control & 0.99 & 0.78 & 0.93 & 0.81 & 0.71 & 0.83 & 0.99 & \\
\hline \multirow{2}{*}{$\begin{array}{l}\text { Maximum plantar flexion } \\
\text { during swing phase }\left({ }^{\circ}\right)\end{array}$} & Study & 0.95 & 0.99 & 0.99 & 0.99 & 0.99 & 0.99 & 0.99 & \multirow{2}{*}{$<0.05$} \\
\hline & Control & 0.89 & 0.51 & 0.99 & 0.97 & 0.91 & 0.58 & 0.88 & \\
\hline \multirow{2}{*}{$\begin{array}{l}\text { Maximum knee flexion } \\
\text { during stance phase }\left({ }^{\circ}\right)\end{array}$} & Study & 0.96 & 0.99 & 0.99 & 0.99 & 0.99 & 0.98 & 0.99 & \multirow{2}{*}{$<0.05$} \\
\hline & Control & 0.99 & 0.89 & 0.83 & 0.67 & 0.54 & 0.93 & 0.99 & \\
\hline \multirow{2}{*}{$\begin{array}{l}\text { Maximum knee extension } \\
\text { during terminal stance phase }\left(^{\circ}\right)\end{array}$} & Study & 0.86 & 0.99 & 0.93 & 0.99 & 0.94 & 0.99 & 0.98 & \multirow{2}{*}{$<0.05$} \\
\hline & Control & 0.49 & -0.05 & 0.84 & 0.95 & 0.99 & 0.03 & 0.47 & \\
\hline \multirow{2}{*}{$\begin{array}{l}\text { Maximum knee flexion } \\
\text { during swing phase }\left(^{\circ}\right)\end{array}$} & Study & 0.97 & 0.99 & 0.99 & 0.98 & 0.99 & 0.98 & 0.99 & \multirow{2}{*}{$<0.05$} \\
\hline & Control & 0.94 & 0.62 & 0.99 & 0.92 & 0.85 & 0.68 & 0.94 & \\
\hline \multirow{2}{*}{$\begin{array}{l}\text { Maximum knee extension } \\
\text { adjacent to heel strike }\left({ }^{\circ}\right)\end{array}$} & Study & 0.98 & 0.99 & 0.99 & 0.98 & 0.99 & 0.97 & 0.99 & \multirow{2}{*}{$<0.05$} \\
\hline & Control & 0.99 & 0.88 & 0.86 & 0.71 & 0.58 & 0.91 & 0.99 & \\
\hline \multirow{2}{*}{$\begin{array}{l}\text { Hip flexion during stance phase } \\
- \text { foot flat }\left({ }^{\circ}\right)\end{array}$} & Study & 0.90 & 0.99 & 0.96 & 0.99 & 0.96 & 0.99 & 0.99 & \multirow{2}{*}{$<0.05$} \\
\hline & Control & 0.74 & 0.27 & 0.97 & 0.99 & 0.99 & 0.34 & 0.73 & \\
\hline \multirow{2}{*}{$\begin{array}{l}\text { Hip flexion during stance phase } \\
- \text { heal off }\left(^{\circ}\right)\end{array}$} & Study & 0.98 & 0.98 & 0.99 & 0.97 & 0.99 & 0.97 & 0.99 & \multirow{2}{*}{$<0.05$} \\
\hline & Control & 0.99 & 0.77 & 0.94 & 0.83 & 0.73 & 0.81 & 0.98 & \\
\hline \multirow{2}{*}{$\begin{array}{l}\text { Maximum hip extension } \\
\text { during midstance phase }\left({ }^{\circ}\right)\end{array}$} & Study & 0.75 & 0.94 & 0.85 & 0.96 & 0.86 & 0.97 & 0.93 & \multirow{2}{*}{$<0.05$} \\
\hline & Control & 0.96 & 0.65 & 0.98 & 0.91 & 0.83 & 0.71 & 0.95 & \\
\hline \multirow{2}{*}{$\begin{array}{l}\text { Maximum hip flexion during } \\
\text { swing phase - heal strike }\left(^{\circ}\right)\end{array}$} & Study & 0.99 & 0.97 & 0.99 & 0.96 & 0.99 & 0.95 & 0.98 & \multirow{2}{*}{$<0.05$} \\
\hline & Control & 0.93 & 0.60 & 0.99 & 0.94 & 0.87 & 0.65 & 0.92 & \\
\hline
\end{tabular}

Spatiotemporal parameters

Gait speed (m/s)

Cadence (steps/min)

Step length (m)

Single support time (\%)

Step length symmetry index*

Single support time symmetry index*

\begin{tabular}{|c|c|c|c|c|c|c|c|c|}
\hline Study & 0.70 & 0.91 & 0.80 & 0.93 & 0.81 & 0.94 & 0.90 & \multirow{2}{*}{$<0.05$} \\
\hline Control & 0.93 & 0.60 & 0.99 & 0.93 & 0.86 & 0.65 & 0.92 & \\
\hline Study & 0.60 & 0.85 & 0.72 & 0.88 & 0.73 & 0.89 & 0.84 & \multirow{2}{*}{$<0.05$} \\
\hline Control & 0.69 & 0.20 & 0.95 & 0.99 & 0.99 & 0.27 & 0.67 & \\
\hline Study & 0.93 & 1.0 & 0.98 & 0.99 & 0.98 & 0.99 & 0.99 & \multirow{2}{*}{$<0.05$} \\
\hline Control & 0.76 & 0.30 & 0.98 & 0.99 & 0.98 & 0.37 & 0.75 & \\
\hline Study & 0.89 & 0.99 & 0.95 & 0.99 & 0.95 & 0.99 & 0.99 & \multirow{2}{*}{$<0.05$} \\
\hline Control & 0.88 & 0.48 & 0.99 & 0.97 & 0.92 & 0.55 & 0.87 & \\
\hline Study & -0.97 & -0.99 & -0.99 & -0.99 & -0.99 & -0.98 & -0.99 & \multirow{2}{*}{$<0.05$} \\
\hline Control & 0.63 & 0.11 & 0.92 & 0.99 & 0.99 & 0.189 & 0.61 & \\
\hline Study & -0.96 & -0.99 & -0.99 & -0.99 & -0.99 & -0.99 & -0.99 & \multirow{2}{*}{$<0.05$} \\
\hline Control & -0.93 & -0.59 & -0.99 & -0.94 & -0.87 & -0.65 & -0.92 & \\
\hline
\end{tabular}




\section{Acknowledgements}

This work was made possible in part by a research grant from the Armenian National Science and Education Fund, based in New York (USA).

\section{Disclosure statement}

No author has any financial interest or received any financial benefit from this research.

\section{Conflict of interest}

The authors state no conflict of interest.

\section{References}

1. van Middelkoop M, Rubinstein SM, Verhagen AP, Ostelo RW, Koes BW, van Tulder MW. Exercise therapy for chronic nonspecific low-back pain. Best Pract Res Clin Rheumatol. 2010;24(2):193-204; doi: 10.1016/j.berh. 2010.01.002.

2. Mayor S. Targeted exercise for muscles that support the spine reduces low back pain, Cochrane review shows. BMJ. 2016;352:i84; doi: 10.1136/bmj.i84.

3. Janda V, Schmid HJA. Muscles as a pathogenic factor in back pain. In: Proceedings of the Fourth Conference of the International Federation of Orthopaedic Manipulative Therapists. Christchurch; 1980; 17-18.

4. Kendall FP, McCreary EK, Provance PG. Muscles: testing and function, $4^{\text {th }}$ ed. Baltimore: Lippincott Williams and Wilkins; 1993.

5. Sahrmann SA. Muscle imbalances in the orthopaedic and neurological patients. In: Proceedings of the $10^{\text {th }}$ International Congress of the World Confederation of Physical Therapy. Sydney; 1987.

6. Sahrmann SA. Posture and muscle imbalance: faulty lumbar-pelvic alignment and associated musculoskeletal pain syndromes. Postgraduate Advances in Physical Therapy. Berryville: Forum Medicum Incorporated; 1987.

7. Stokes $M$, Young A. The contribution of reflex inhibition to arthrogenous muscle weakness. Clin Sci. 1984;67(1):714; doi: $10.1042 / c s 0670007$.

8. Albeck MJ, Taher G, Lauritzen M, Trojaborg W. Diagnostic value of electrophysiological tests in patients with sciatica. Acta Neurol Scand. 2000;101(4):249-254; doi: 10.1034/j.1600-0404.2000.101004249.x.

9. Koceja DM, Trimble MH, Earles DR. Inhibition of the soleus H-reflex in standing man. Brain Res. 1993;629(1): 155-158; doi: 10.1016/0006-8993(93)90495-9.

10. Aagaard $P$, Simonsen EB, Andersen JL, Magnusson $P$, Dyhre-Poulsen P. Neural adaptation to resistance training: changes in evoked $\mathrm{V}$-wave and $\mathrm{H}$-reflex responses. J Appl Physiol. 2002;92(6):2309-2318; doi: 10.1152/ japplphysiol.01185.2001.

11. Angulo-Kinzler RM, Mynark RG, Koceja DM. Soleus H-reflex gain in elderly and young adults: modulation due to body position. J Gerontol A Biol Sci Med Sci. 1998;53(2): 120-125; doi: 10.1093/gerona/53a.2.m120.

12. Capaday C, Stein RB. Amplitude modulation of the soleus $\mathrm{H}$-reflex in the human during walking and standing. J Neurosci. 1986;6(5):1308-1313; doi: 10.1523/JNEUROSCI.06-05-01308.1986.

13. Cheng J, Brooke JD, Misiaszek JE, Staines WR. The relationship between the kinematics of passive movement, the stretch of extensor muscles of the leg and the change induced in the gain of the soleus $\mathrm{H}$ reflex in humans. Brain Res. 1995;672(1):89-96; doi: 10.1016/0006-8993 (94)01321-8.
14. Gruber M, Taube W, Gollhofer A, Beck S, Amtage F, Schubert $\mathrm{M}$. Training-specific adaptations of $\mathrm{H}$ - and stretch reflexes in human soleus muscle. J Motor Behav. 2007;39(1):68-78; doi: 10.3200/JMBR.39.1.68-78.

15. Misiaszek JE, Cheng J, Brooke JD, Staines WR. Movement-induced modulation of soleus $\mathrm{H}$ reflexes with altered length of biarticular muscles. Brain Res. 1998; 795(1-2):25-36; doi: 10.1016/s0006-8993(98)00246-7.

16. Larsen B, Mrachacz-Kersting N, Lavoie BA, Voigt M. The amplitude modulation of the quadriceps $\mathrm{H}$-reflex in relation to the knee joint action during walking. Exp Brain Res. 2006;170(4):555-566; doi: 10.1007/s00221-0050237-1.

17. Morag E, Hurwitz DE, Andriacchi TP, Hickey M, Andersson GB. Abnormalities in muscle function during gait in relation to the level of lumbar disc herniation. Spine. 2000;25(7):829-833; doi: 10.1097/00007632-2000040 10-00011.

18. Simonsen EB, Dyhre-Poulsen P. Amplitude of the human soleus $\mathrm{H}$ reflex during walking and running. J Physiol. 1999;515(Pt3):929-939; doi:10.1111/j.1469-7793.1999. 929ab.x

19. Kyröläinen H, Avela J, Komi PV. Changes in muscle activity with increasing running speed. J Sports Sci. 2005; 23(10):1101-1109; doi: 10.1080/02640410400021575.

20. Simonsen EB, Alkjær T, Raffalt PC. Reflex response and control of the human soleus and gastrocnemius muscles during walking and running at increasing velocity. Exp Brain Res. 2012;219(2):163-174; doi: 10.1007/ s00221-012-3075-y.

21. Racic V, Brownjohn JMW, Pavic A. Reproduction and application of pedestrian forces from visual marker data. In: Proceedings of the IUTAM symposium on analysis and simulation of human motion. Leuven, 13-15 Sep 2010.

22. Groll DL, To T, Bombardier C, Wright JG. The development of a comorbidity index with physical function as the outcome. J Clin Epidemiol. 2005;58(6):595-602; doi: 10.1016/j.jclinepi.2004.10.018.

23. Burke GL. Backache from occiput to coccyx. Vancouver: W.E.G. Macdonald; 1964.

24. Ogwumike OO, Musa SB. Relationships among walking speed, selected clinical symptoms, and exercise selfefficacy in individuals with knee osteoarthritis. Hum Mov. 2019;20(2):79-84; doi: 10.5114/hm.2019.81023.

25. Łozińska $P$, Wójtowicz $D$, Wdowiak $P$, Dziuba-Słonina $A$. Changes in kinematic parameters during walking in adults with low back pain subjected to Vojta therapy. A pilot study. Physiother Quart. 2019;27(2):22-28; doi: 10.5114/pq.2019.84273.

26. Bennett HJ, Valenzuela KA, Fleenor K, Morrison S, Haegele JA. Walking biomechanics and energetics of individuals with a visual impairment: a preliminary report. Hum Mov. 2019;20(4):8-18; doi: 10.5114/hm.2019.85094. 